\title{
Implementation of Delay and Power Monitoring Schemes to Reduce the Power Consumption
}

\author{
Pavan.T.K. \\ M.Tech. (VLSI Design) \\ T.N, India
}

\author{
Jagannadha Naidu.K \\ Asst.Prof, VIT University \\ T.N, India
}

\author{
Nagaraju.V \\ M.Tech, VIT University \\ T.N, India
}

\begin{abstract}
As process technology shrinks, the adaptive leakage power compensation scheme will become more important in realizing high-performance and low-power applications. In order to minimize total active power consumption in digital circuits, one must take into account sub-threshold leakage currents that grow exponentially as technology scales. This describes to predict how dynamic power and sub-threshold power must be balanced. The exclusive supply voltage control switching makes stable operations. The threshold voltage control successfully maintains a ratio of switching to leakage current and which represents the reduced power consumption. The goal of this paper is to: i) Maintains the optimized body bias conditions. ii) Maintains the best power-delay tradeoff. The results with a 180-nm CMOS device explain that the proposed architecture causes in the successful optimization of power.
\end{abstract}

\section{Keywords}

CMOS, leakage current, supply voltage control, threshold voltage control, switching current.

\section{INTRODUCTION}

The effects of scaled $V_{d d}$ and gate oxide tunneling leakage in order to achieve optimized body bias values in standby system. The dual $V_{\text {th }}$ technique provides a practical way to achieve both high performance and low leakage power dissipation for current deep submicron technology. The $\mathrm{V}_{\mathrm{dd}}$ was controlled to control the propagation delay in the chip core critical path. And in the chip core we can implement any design whatever we need based on the specification. The control of $\mathrm{V}_{\text {th }}$ was to compensate for $\mathrm{V}_{\text {th }}$ fluctuations, in order to avoid any oscillation problems. To determine the effects of process variations on the leakage reduction, two parameters will be varied and namely the gate length and BTBT current. Therefore, new junction engineering techniques to reduce the bulk Band-To-Band Tunneling leakage across the junction will be essential to preserve the performance. As the power monitoring scheme directly measures relative power from circuit.

This paper is summarized as follows. Section 2 describes the power monitoring schemes. Section 3 explains the block diagram of $\mathrm{V}_{\mathrm{dd}} / \mathrm{V}_{\text {th }}$ control system. Section 4 explains in detail our proposed delay and power monitors for the active mode, as well as standby mode. Section 5 shows Measurement results. Section 6 describes about the conclusion.

\section{THE POWER MONITORING SCHEMES 2.1 Current consumption in Active mode}

The active current equation of static CMOS described as the following equation.

$\mathrm{I}_{\text {active }}=\mathrm{I}_{\text {sw }}+\mathrm{I}_{\text {leak }}$

Where $\mathrm{I}_{\mathrm{sw}}=$ switching current and $\mathrm{I}_{\text {leak }=\text { leakage current. }}$

\subsection{The Principle of Power monitoring}

Fig.1. gives the relationships among $\mathrm{I}_{\mathrm{A}}, \mathrm{I}_{\mathrm{B}}$ and $\mathrm{I}_{\mathrm{SUM}}$. $\mathrm{I}_{\mathrm{A}}$ and $\mathrm{I}_{\mathrm{B}}$ are straight lines. $\mathrm{I}_{\mathrm{SUM}}$ is the sum of $\mathrm{I}_{\mathrm{A}}$ and $\mathrm{I}_{\mathrm{B}}$ as described in the following equations:

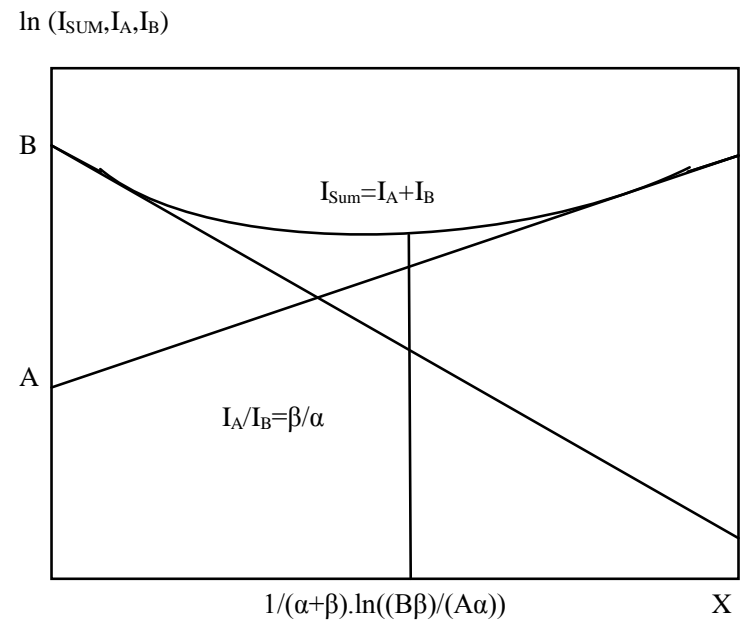

Figure 1: Relationships among $I_{A}, I_{B}$ and $I_{S U M}$.

$\mathrm{I}_{\mathrm{SUM}}(\mathrm{x})=\mathrm{I}_{\mathrm{A}}(\mathrm{x})+\mathrm{I}_{\mathrm{B}}(\mathrm{x})$

Where $\mathrm{I}_{\mathrm{A}}(\mathrm{x})=\mathrm{A} \cdot \exp (\alpha \mathrm{x})$ and $\mathrm{I}_{\mathrm{B}}(\mathrm{x})=\mathrm{B} \cdot \exp (-\beta \mathrm{x})$.

Finally, $\mathrm{x}$ can be calculated as

$\mathrm{I}_{\mathrm{SUM}}(\mathrm{x})^{\prime}=\mathrm{A} \alpha \cdot \exp (\alpha \mathrm{x})-\mathrm{B} \beta \cdot \exp (-\beta \mathrm{x})=0$

Therefore,

$x=1 /(\alpha+\beta) \cdot \ln (B \beta / A \alpha)$

The value of $\mathrm{I}_{\mathrm{SUM}}$ can be determined as

$\mathrm{I}_{\mathrm{A}}(\mathrm{x}) / \mathrm{I}_{\mathrm{B}}(\mathrm{x})=\beta / \alpha$

At the minimum value of $\mathrm{I}_{\mathrm{SUM}}$, the ratio $\mathrm{I}_{\mathrm{A}} / \mathrm{I}_{\mathrm{B}}$ can be determined. 


\subsection{Current consumption in Standby mode}

The leakage current in standby mode can be represented as the following equation.

$\mathrm{I}_{\text {leak }}=\mathrm{I}_{\text {subth }}+\mathrm{I}_{\text {sub }}+\mathrm{I}_{\mathrm{dg}}$

Where $I_{\text {subth }}$ is the sub-threshold current, $I_{\text {sub }}$ is the substrate current and which is the sum of gate to bulk leakage and gate induced drain leakage. And $\mathrm{I}_{\mathrm{dg}}$ is the drain-gate leakage current. The minimum $\mathrm{I}_{\text {leak }}$ will be achieved at $\mathrm{I}_{\text {subth }}=\mathrm{I}_{\text {sub }}$. While reverse body bias decreases $I_{\text {subth }}$, it increases $I_{\text {sub }}$ and does not affect $I_{d g}$.

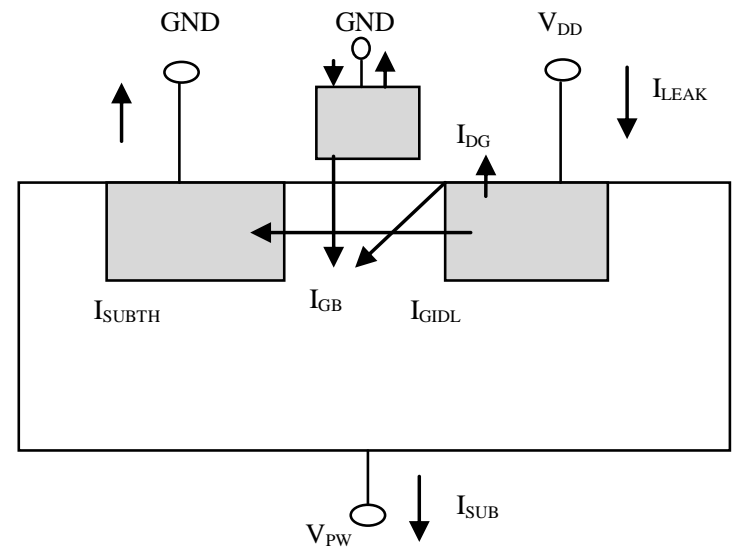

Figure 2: When the MOS is in OFF state.

Each leakage current depends on $\mathrm{V}_{\mathrm{DD}}$. Decreasing $\mathrm{V}_{\mathrm{DD}}$ will reduce the value of leakage current components such as $\mathrm{I}_{\mathrm{SUB}}$ and $\mathrm{I}_{\mathrm{DG}}$. The minimum value of $\mathrm{I}_{\text {LEAK }}$ gives a tradeoff between $\mathrm{I}_{\mathrm{SUBTH}}$ and $\mathrm{I}_{\mathrm{SUB}}$.

\section{3. $\mathrm{V}_{\mathrm{DD}} / \mathrm{V}_{\mathrm{TH}}$ CONTROL SYSTEM DESIGN}

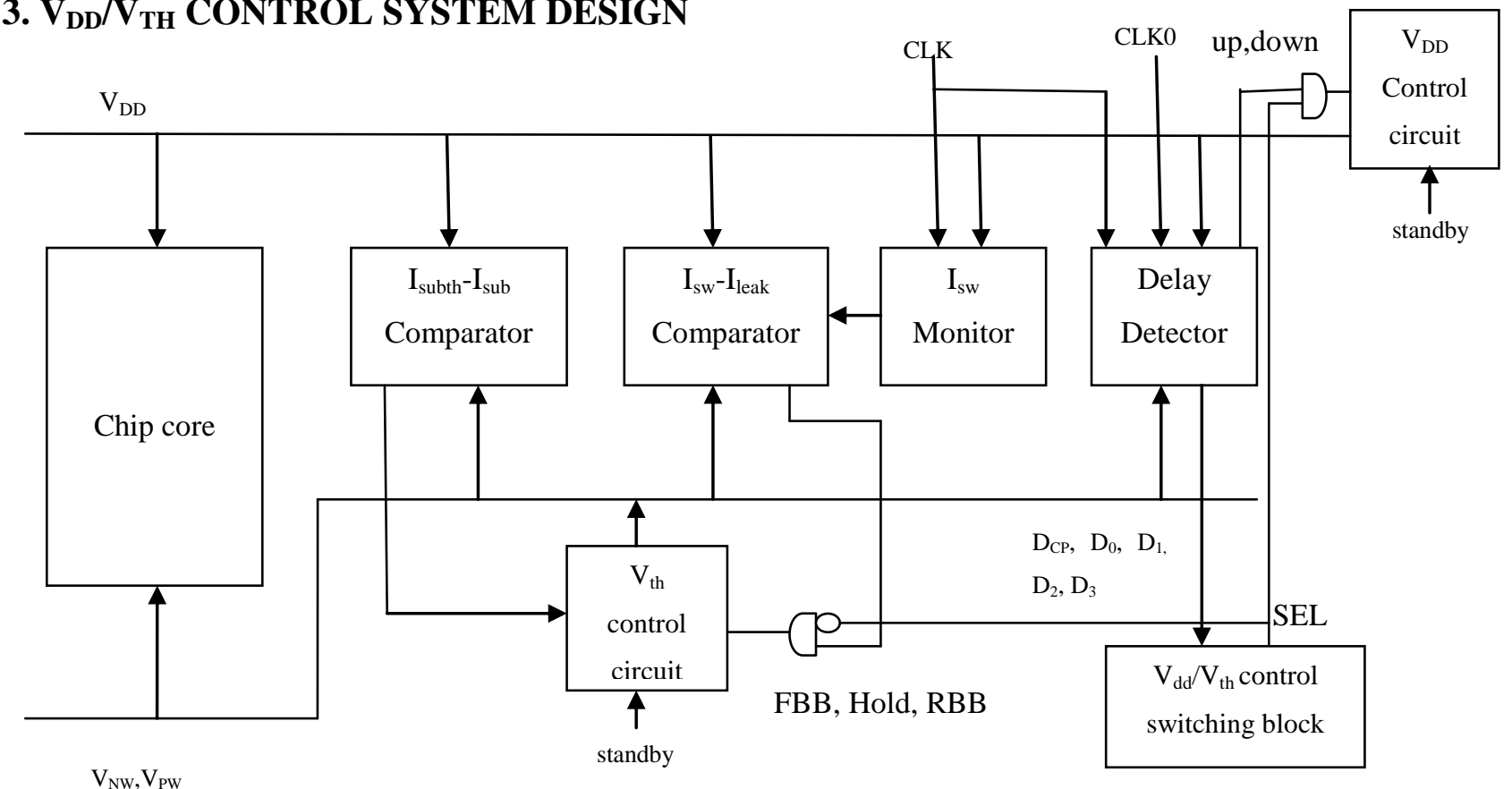

Figure 3: The Block Diagram of $V_{d d} / V_{\text {th }}$ control system.

The above diagram explains in detail about the total block diagram of $\mathrm{V}_{\mathrm{dd}} / \mathrm{V}_{\mathrm{th}}$ control system. It is necessary for a $\mathrm{V}_{\mathrm{DD}} / \mathrm{V}_{\text {th }}$ control system not only to achieve minimum power consumption but also to satisfy speed performance demands. $\mathrm{V}_{\mathrm{DD}}$ control is highly sensitive and has wide speed control range. $\mathrm{V}_{\text {th }}$ control or $\mathrm{V}_{\mathrm{PW}}, \mathrm{V}_{\mathrm{NW}}$ control has low sensitivity with respect to speed and is highly sensitive with respect to sub-threshold leakage current.. Here $\mathrm{V}_{\mathrm{DD}}$ control is used to help satisfy speed performance demands and $\mathrm{V}_{\text {th }}$ control to help achieve minimum power consumption, so as to maintain the desired $\mathrm{I}_{\mathrm{SW}} / \mathrm{I}_{\text {leak }}$ ratio. The $\mathrm{V}_{\mathrm{DD}}$ and $\mathrm{V}_{\text {th }}$ control system is illustrated in the above figure. And it consists of four parts: i) $V_{D D}$ controller. ii) $V_{\text {th }}$ controller. iii) Delay monitor that contains a delay detector and a $V_{D D} / V_{t h}$ control switching block. iv) Power monitor that contains an $\mathrm{I}_{\mathrm{SW}}$ monitor, $\mathrm{I}_{\mathrm{SW}}-\mathrm{I}_{\text {leak }}$ comparator and an $\mathrm{I}_{\text {subth }}-\mathrm{I}_{\text {sub }}$ comparator. The $\mathrm{V}_{\mathrm{DD}}$ controller supplies, on the basis of delay monitoring results, the minimum voltage at which the chip can operate for a given clock frequency at a certain $\mathrm{V}_{\text {th }}$. The $\mathrm{V}_{\text {th }}$ controller supplies, on the basis of power monitoring results, the optimum body bias at which the chip consumes minimum power at a certain $\mathrm{V}_{\mathrm{DD}}$, and for which the chip can operate with a desired $\mathrm{I}_{\mathrm{Sw}} / \mathrm{I}_{\text {leak }}$ ratio in the active mode and with $\mathrm{I}_{\text {subth }}=\mathrm{I}_{\text {sub }}$ in the standby mode. And this control system design is very useful in both active and standby modes to reduce any type of power consumption. And we will see all these in detail below sections. 


\section{MONITOR CIRCUITS}

\subsection{Delay Monitor}

It is a combination of both the delay detector and $\mathrm{V}_{\mathrm{DD}} / \mathrm{V}_{\text {th }}$ Control switching block. And these are mainly used to control the delay based on the design in chip core.

\subsubsection{Delay Detector}

The Delay Detector is a circuit used to detect the relationship between clock cycle time and propagation delay in the chip core's critical path, controls the $\mathrm{V}_{\mathrm{DD}}$ controller and the $\mathrm{V}_{\mathrm{DD}} / \mathrm{V}_{\mathrm{th}}$ control switching block. And the delay detector circuit is shown in the below figure. The delay detector circuit consists of a critical path circuit, delay circuits (D), and registers. CLK is the clock signal of the internal circuits, CLK0 is a sampling clock for $\mathrm{V}_{\mathrm{DD}} / \mathrm{V}_{\text {th }}$ control, and Data is a one-shot pulse signal in a cycle of CLK synchronous CLK0s. $\mathrm{D}_{\mathrm{cp}}$ and $\mathrm{D}_{0-3}$ are comparator result signals, indicating differences between clock period $\mathrm{T}_{\mathrm{CLK}}$ and various path delays that include, respectively, delay margins $t_{c p}$ and $t_{0-3}$, where $t_{c p}$ is delay in a critical path replica. If $t_{*}<T_{C L K}$ is true, $D_{*}$ will be 1 . Up, Down and Err are control signals used in $\mathrm{V}_{\mathrm{DD}}$ control. If $\mathrm{D}_{1}=0$, Up will be 1 . If $\mathrm{D}_{2}=1$, Down will be 1 .
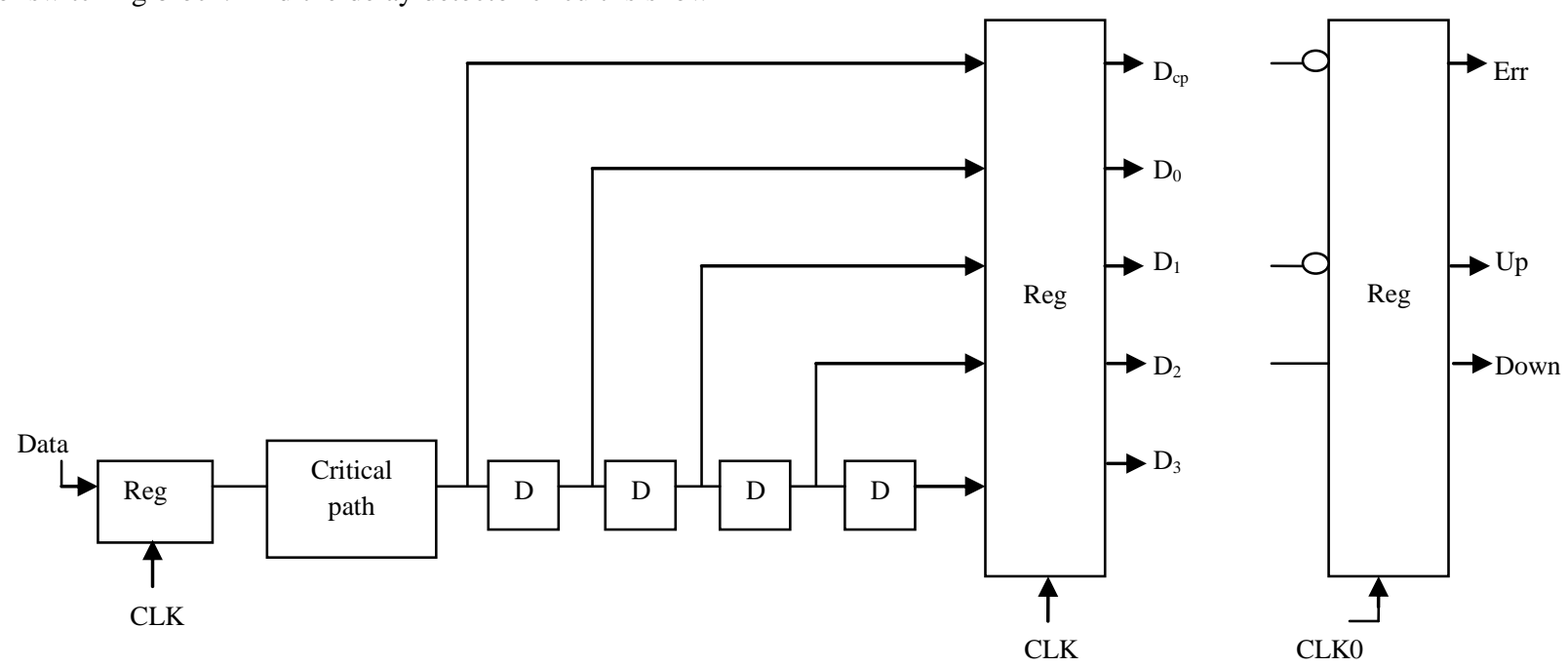

Figure 4: The Delay detector circuit.

\subsection{2 $V_{D D} / V_{\text {th }}$ control switching block}

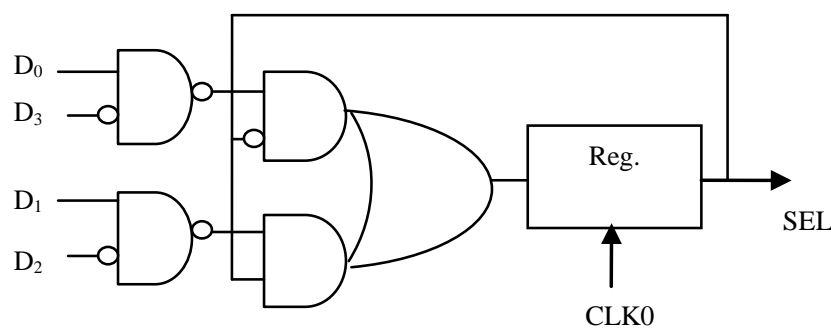

Figure 5: The $V_{\text {dd }} / V_{\text {th }}$ control switching block.

As the name indicates, the $\mathrm{V}_{\mathrm{dd}} / \mathrm{V}_{\text {th }}$ control selection block selects either $\mathrm{V}_{\mathrm{dd}}$ control or $\mathrm{V}_{\text {th }}$ control. SEL is the $\mathrm{V}_{\mathrm{dd}} / \mathrm{V}_{\text {th }}$ control selection signal. If $\mathrm{SEL}=1$ represents the $\mathrm{V}_{\mathrm{dd}}$ control mode and $\mathrm{SEL}=0$ indicates the $\mathrm{V}_{\mathrm{th}}$ control mode to avoid any oscillation problems. Figure 5. gives the architecture of $\mathrm{V}_{\mathrm{dd}} / \mathrm{V}_{\mathrm{th}}$ control selection block. In $\mathrm{V}_{\mathrm{DD}}$ control $\operatorname{SEL}(-1)=1$, where $\operatorname{SEL}(-1)$ indicates the previous state, if $\left(D_{1} D_{2}\right)=(10), t_{1}<T_{C L K}<t_{2}$ is true, $\mathrm{V}_{\mathrm{DD}}$ control will stop and $\mathrm{V}_{\mathrm{th}}$ control will start. $\operatorname{SEL}(0)=0$, where SEL(0) indicates the current state. In $\mathrm{V}_{\mathrm{th}}$ control (SEL(-1)=0), if $\mathrm{D}_{0}=0$ or $\mathrm{D}_{3}=1, \mathrm{~T}_{\mathrm{CLK}}<\mathrm{t}_{0}$ or $\mathrm{t}_{3}<\mathrm{T}_{\mathrm{CLK}}$ is true, $\mathrm{V}_{\mathrm{th}}$ control will stop and $\mathrm{V}_{\mathrm{DD}}$ control will start. The table 1 indicates the truth table of $\mathrm{V}_{\mathrm{dd} /} \mathrm{V}_{\text {th }}$ control selection block and which explains all the operations involved in both the blocks.
Table 1: Truth table of $V_{d d} / V_{\text {th }}$ control switching block.

\begin{tabular}{|c|c|c|c|c|c|c|c|}
\hline $\operatorname{Sel}(-1)$ & $\mathrm{D}_{\mathrm{cp}}$ & $D_{0}$ & $\mathrm{D}_{1}$ & $\mathrm{D}_{2}$ & $\mathrm{D}_{3}$ & $\operatorname{Sel}(0)$ & Operations \\
\hline \multirow[t]{2}{*}{$\mathrm{V}_{\text {th }}$ control } & 0 & 0 & 0 & 0 & 0 & 1 & $\mathrm{~V}_{\mathrm{dd}}$ up err \\
\hline & 1 & 0 & 0 & 0 & 0 & 1 & $\mathrm{~V}_{\mathrm{dd}} \mathrm{up}$ \\
\hline \multirow[t]{4}{*}{$\operatorname{Sel}(-1)=0$} & 1 & 1 & 0 & 0 & 0 & 0 & $\mathrm{~V}_{\text {th }}$ control \\
\hline & 1 & 1 & 1 & 0 & 0 & 0 & $\mathrm{~V}_{\text {th }}$ control \\
\hline & 1 & 1 & 1 & 1 & 0 & 0 & $\mathrm{~V}_{\text {th }}$ control \\
\hline & 1 & 1 & 1 & 1 & 1 & 1 & $\mathrm{~V}_{\mathrm{dd}}$ down \\
\hline \multirow[t]{2}{*}{$\mathrm{V}_{\mathrm{dd}}$ control } & 0 & 0 & 0 & 0 & 0 & 1 & $\mathrm{~V}_{\mathrm{dd}}$ up err \\
\hline & 1 & 0 & 0 & 0 & 0 & 1 & $V_{\text {dd }}$ up \\
\hline \multirow[t]{4}{*}{$\operatorname{Sel}(-1)=1$} & 1 & 1 & 0 & 0 & 0 & 1 & $\mathrm{~V}_{\mathrm{dd}}$ up \\
\hline & 1 & 1 & 1 & 0 & 0 & 0 & $\mathrm{~V}_{\text {th }}$ control \\
\hline & 1 & 1 & 1 & 1 & 0 & 1 & $\mathrm{~V}_{\mathrm{dd}}$ down \\
\hline & 1 & 1 & 1 & 1 & 1 & 1 & $\mathrm{~V}_{\mathrm{dd}}$ down \\
\hline
\end{tabular}




\subsection{Active Power Monitor}

The power monitor, a circuit for monitoring minimum chip power consumption, controls the $\mathrm{V}_{\text {th }}$ controller. It mainly involves 2 parts such as $\mathrm{I}_{\mathrm{SW}}$ Monitor, $\mathrm{I}_{\mathrm{SW}^{-}} \mathrm{I}_{\text {leak }}$ Comparator. And these are explained below.

\subsection{1 $\mathrm{I}_{S W}$ Monitor}

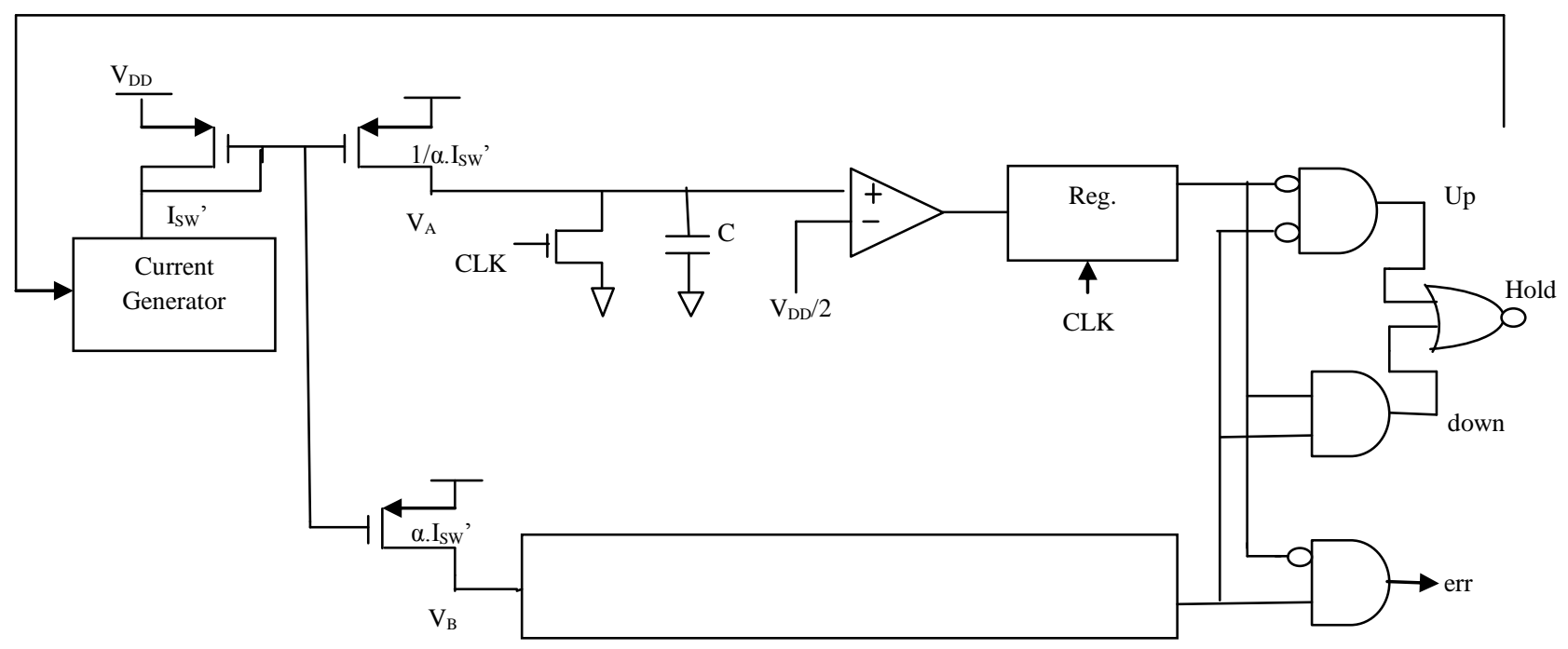

Figure 5: The $\mathbf{I}_{S W}$ Monitor circuit.

The outputs of the comparators, which detect $\mathrm{V}_{\mathrm{DD}} / 2$ levels, are latched at rise clock edges. $\mathrm{I}_{\mathrm{SW}}$ may be expressed as

$\mathrm{I}_{\mathrm{sw}}=\mathrm{C} \cdot \mathrm{V}_{\mathrm{DD}} / 2 \cdot 2 \mathrm{f}=\mathrm{C} \cdot \mathrm{V}_{\mathrm{DD}} \cdot \mathrm{f}$

\subsection{2 $I_{S W}-I_{\text {leak }}$ Comparator}

The $\mathrm{I}_{\mathrm{SW}}-\mathrm{I}_{\text {leak }}$ comparator then compares the $\mathrm{I}_{\text {leak }}$ values of leakage current replicas with $\mathrm{I}_{\mathrm{SW}}$, and the $\mathrm{V}_{\text {th }}$ control circuit adjusts body biases $\mathrm{V}_{\mathrm{NW}}$ and $\mathrm{V}_{\mathrm{PW}}$ on the basis of the comparison results. The results it produces are used to control body biases $\left(\mathrm{V}_{\mathrm{NW}}\right.$ and $\left.\mathrm{V}_{\mathrm{PW}}\right)$ so that leakage current will be maintained within the range of $\beta$. $\mathrm{I}_{\mathrm{SW}}$ ' to $1 / \beta$. $\mathrm{I}_{\mathrm{SW}}$, where $0<\beta<1$. Majority-decision circuits are employed so as to avoid any problems resulting from abnormal leakage current due to device defects. $\mathrm{V}_{\mathrm{PW}}\left(\mathrm{V}_{\mathrm{NW}}\right)$ is controlled in the range between $\mathrm{RBB}$ and $\mathrm{FBB}$ If $\mathrm{I}_{\text {leak }}<\mathrm{I}_{\mathrm{SW}}$ ' is true, FBB_PW (FBB_NW) will be 1 and $\mathrm{V}_{\mathrm{PW}}\left(\mathrm{V}_{\mathrm{NW}}\right)$ will change in the direction of $\mathrm{FBB}$. If $\mathrm{I}_{\text {leak }}>\mathrm{I}_{\mathrm{SW}}$ ' is true, RBB_PW (RBB_NW) will be 1 and $\mathrm{V}_{\mathrm{PW}}\left(\mathrm{V}_{\mathrm{NW}}\right)$ will change in the direction of RBB. $V_{\text {th }}$ control affects not only leakage current but also circuit delay. If $t_{0}<T_{C L K}<t_{3}$, which is a maximum permissible condition, is not true, $\mathrm{V}_{\mathrm{DD}}$ control will start immediately and guarantee $t_{c p}<T_{C L K}$. And the architecture is shown in the following figure 6 .

\subsubsection{Standby Power Monitor}

In the standby mode, the $V_{\text {th }}$ controller increases $V_{\text {th }}$ by adjusting $\mathrm{V}_{\mathrm{PW}}$ and $\mathrm{V}_{\mathrm{NW}}$ in the $\mathrm{RBB}$ direction, so as to reduce sub-threshold leakage current $\mathrm{I}_{\text {subth }}$. When the optimum body bias is detected, $\mathrm{V}_{\mathrm{NW}}$ and $\mathrm{V}_{\mathrm{PW}}$ adjustment is stopped to avoid
The $\mathrm{I}_{\mathrm{SW}}$ monitor is a key component of power monitor. In $\mathrm{V}_{\text {th }}$ control, the $\mathrm{I}_{\mathrm{SW}}$ monitor quickly generates a reference current $\mathrm{I}_{\mathrm{SW}}$ ' proportional to both clock frequency and supply voltage. When $C L K=1$, pre-discharge nMOSFETs discharge dynamic nodes and $\mathrm{V}_{\mathrm{A}}$ and $\mathrm{V}_{\mathrm{B}}$. When CLK changes from 1 to $0, \mathrm{~V}_{\mathrm{A}}$ and $\mathrm{V}_{\mathrm{B}}$ increase with the flow of $1 / \alpha . \mathrm{I}_{\mathrm{sw}}{ }^{\prime}$ and $\alpha . \mathrm{I}_{\mathrm{sw}}$ ', where $0<\alpha<1$ and the value of $\alpha$ determines the precision of $\mathrm{I}_{\mathrm{SW}}$.
Table 2: Truth table of Current Generator.

\begin{tabular}{|c|c|c|}
\hline $\mathrm{V}_{\mathrm{A}}$ & $\mathrm{V}_{\mathrm{B}}$ & Operations \\
\hline 0 & 0 & Isw' Up \\
\hline 0 & 1 & Prohibition \\
\hline 1 & 0 & Isw' Hold \\
\hline 1 & 1 & Isw' Down \\
\hline
\end{tabular}

excessive reverse body bias. Fig.11 illustrates this circuit, whicl is an $\mathrm{I}_{\text {subth }}-\mathrm{I}_{\text {sub }}$ comparator circuit for nMOSFETs.

\subsubsection{1 $I_{\text {subth }}-I_{\text {sub }}$ comparator}

It compares half the drain current of the left-side nMOSFET with the drain current of a right-side nMOSFET, and also compares the $\left(\mathrm{I}_{\text {subth }} / 2-\mathrm{I}^{\prime}{ }_{\text {subth }} \mathrm{I}_{\mathrm{dg}} / 2\right)$ to $\left(\mathrm{I}_{\text {gidl }} / 2\right)$. Where $\mathrm{I}_{\text {subth }}$ is the right side nMOSFET of sub-threshold current, $\mathrm{I}_{\mathrm{DG}}$ is drain-togate leakage current. There are three problems with this circuit: First, operation of the current mirror produces in a drop in drain voltage $\left(V_{\text {drain }}\right)$, which results in erroneous values for $\mathrm{I}_{\text {subth }}$ and $I_{\text {sub. }}$ Second, both $I_{\text {subth }}$ and $I_{D G}$ are included in the value calculated for $\mathrm{I}_{\text {subth }}$ which makes it erroneous. And third, the value for $\mathrm{I}_{\text {sub }}$ becomes erroneous because $\mathrm{I}_{\mathrm{GB}}$ is ignored in this calculation. And the architecture is shown the following figure 7. And the above problems can be overcome by the modified architecture and is shown the below figure 8 . And which gives more precision than the normal comparator and reduced the voltage drop much. 


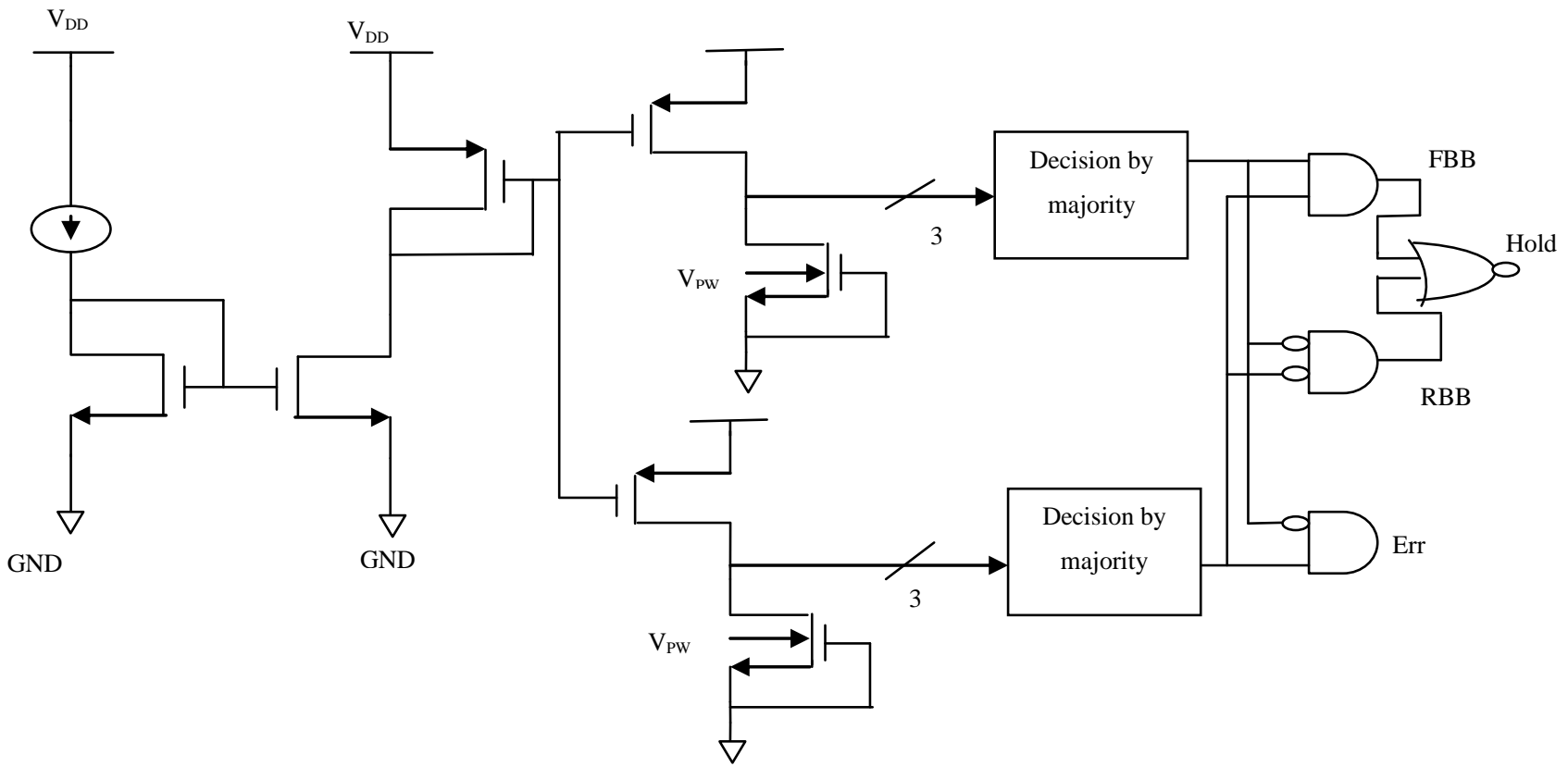

Figure 6: The $\mathbf{I}_{\mathrm{SW}}-\mathrm{I}_{\mathrm{LEAK}}$ Comparator circuit.

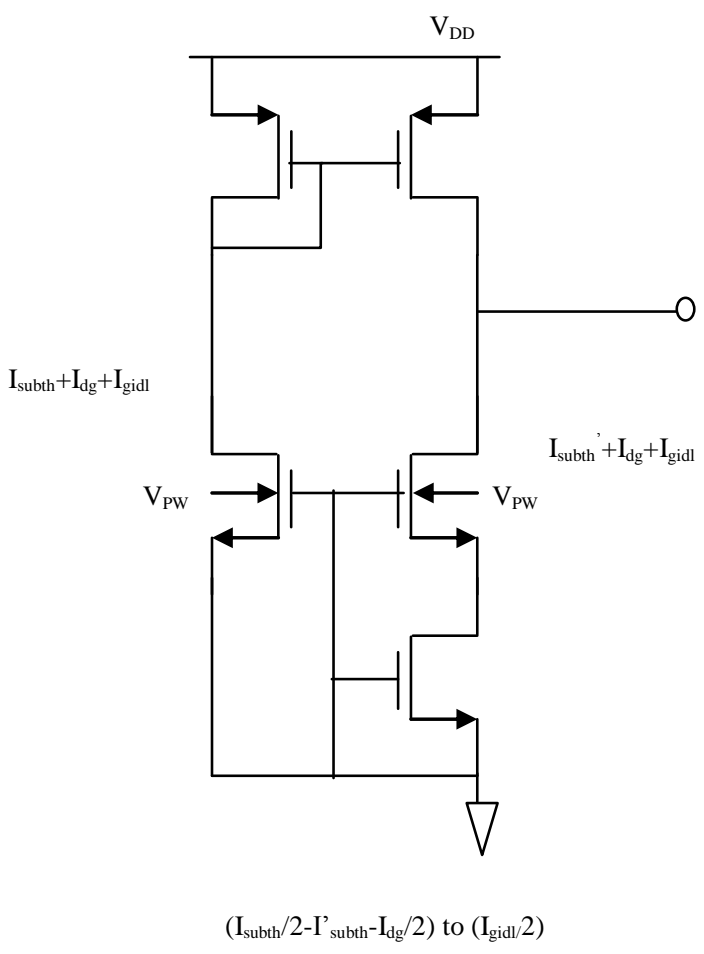

Figure 7: The $\mathbf{I}_{\text {Subth }}-\mathbf{I}_{\text {sub }}$ Comparator circuit.

Our modified $\mathrm{I}_{\text {Subth }}-\mathrm{I}_{\text {sub }}$ comparator circuit for optimum body bias monitoring of nMOSFETs. And it has overcome the above mentioned problems such as the reduction of voltage drop. In it, in order to achieve optimum body bias, we have taken into consideration the effects of lowering $\mathrm{V}_{\mathrm{DD}}$ values and the effects of the presence of gate-oxide leakage. It maintains the $\mathrm{V}_{\text {drain }}$ of

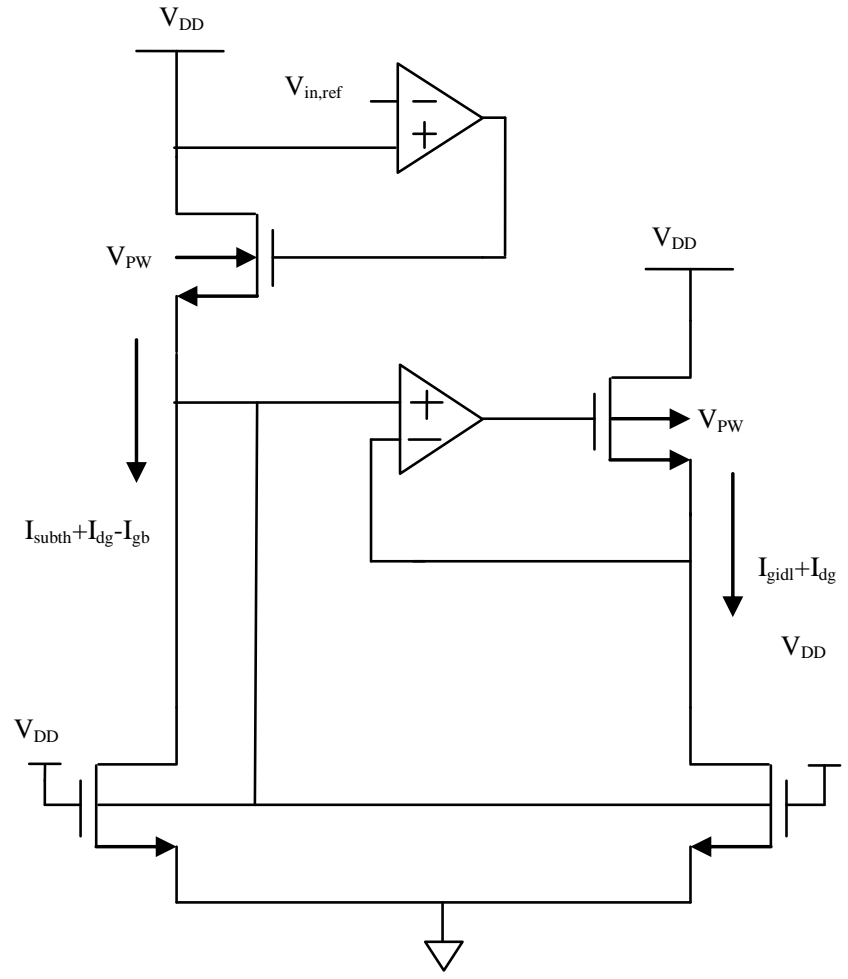

Figure 8: The modified $I_{\text {Subth }}-I_{\text {sub }}$ Comparator circuit.

$\mathrm{V}_{\mathrm{DD}}$, monitors the source current (not the drain current of its left-side nMOSFET), and floats the source terminal for its rightside nMOSFET. The difference between the left nMOSFET's source current $\left(\mathrm{I}_{\text {subth }}+\mathrm{I}_{\mathrm{DG}}-\mathrm{I}_{\mathrm{GB}}\right)$ and the right nMOSFET's drain current $\left(\mathrm{I}_{\mathrm{GIDL}}+\mathrm{I}_{\mathrm{DG}}\right)$ serves as a monitor of $\mathrm{I}_{\text {subth }}$ versus $\mathrm{I}_{\text {sub }}$, which equals $\left(\mathrm{I}_{\mathrm{GIDL}}+\mathrm{I}_{\mathrm{GB}}\right)$. 


\section{MEASUREMENT RESULTS}
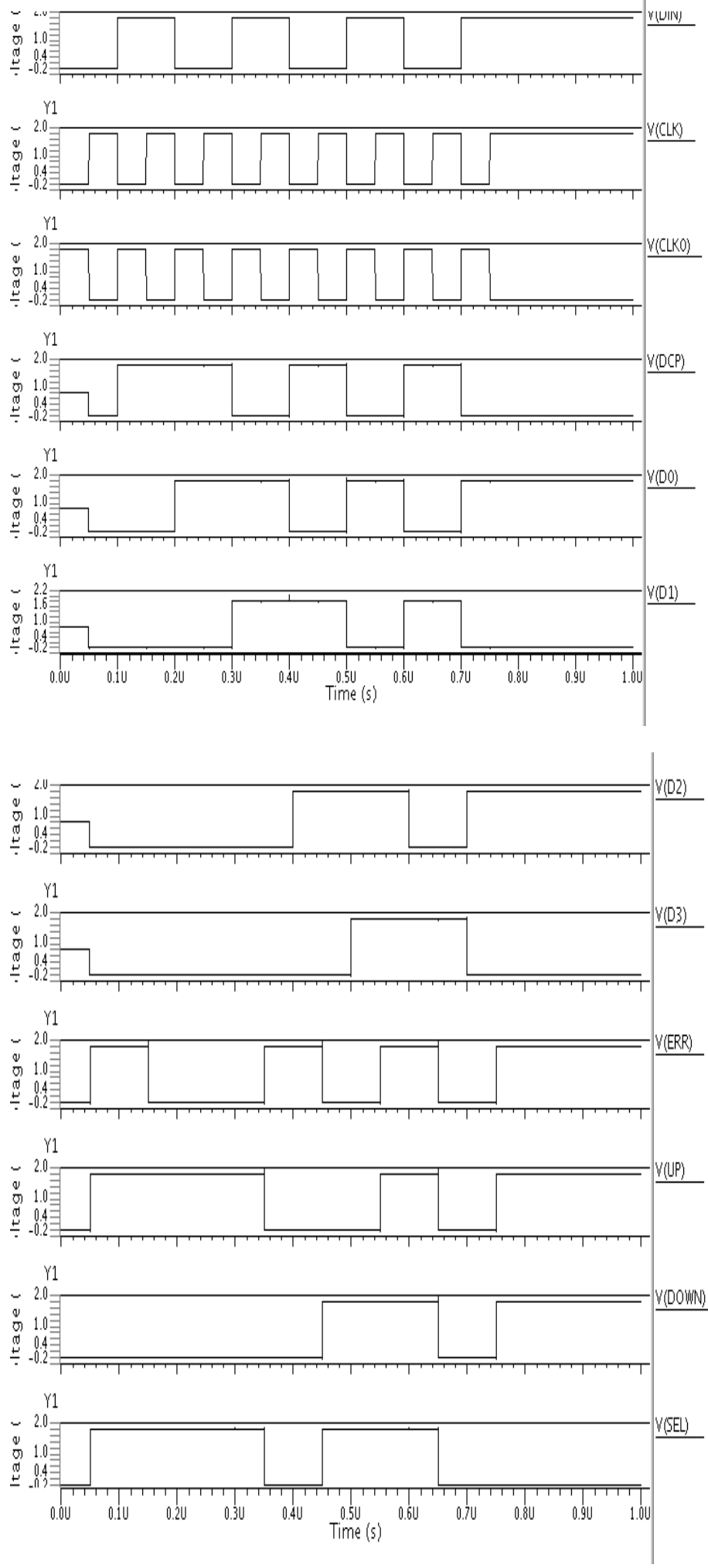

Figure 9: The Results of Delay monitor.
Table 3: The Leakage power consumption of all blocks.

\begin{tabular}{|c|c|c|}
\hline Module name & Leakage current & Leakage power \\
\hline Delay Detector & $61.3 \mathrm{nA}$ & $0.101 \mathrm{uW}$ \\
\hline $\mathrm{V}_{\mathrm{DD}} / \mathrm{V}_{\text {th }}$ control block & $18.1 \mathrm{nA}$ & $0.032 \mathrm{uW}$ \\
\hline $\mathrm{V}_{\mathrm{DD}}$ control circuit & $150.4 \mathrm{nA}$ & $0.272 \mathrm{uW}$ \\
\hline $\mathrm{V}_{\text {th }}$ control circuit & $250.8 \mathrm{pA}$ & $0.451 \mathrm{nW}$ \\
\hline $\mathrm{I}_{\mathrm{sw}}$ monitor & $277.6 \mathrm{nA}$ & $0.499 \mathrm{uW}$ \\
\hline $\mathrm{I}_{\mathrm{sw}}-\mathrm{I}_{\text {leak }}$ comparator & $135.2 \mathrm{pA}$ & $0.243 \mathrm{nW}$ \\
\hline $\mathrm{I}_{\text {subth }}-\mathrm{I}_{\text {sub }}$ comparator & $182.7 \mathrm{nA}$ & $0.328 \mathrm{uW}$ \\
\hline${\text { Modified } \mathrm{I}_{\text {subth }}-\mathrm{I}_{\text {sub }}}$ & $217.6 \mathrm{nA}$ & $0.391 \mathrm{uW}$ \\
\hline
\end{tabular}

Table 4: The Total Power consumption of all blocks.

\begin{tabular}{|l|l|}
\hline Module name & Power consumption \\
\hline Delay Detector & $1.775 \mathrm{uW}$ \\
\hline $\mathrm{V}_{\mathrm{DD}} / \mathrm{V}_{\text {th }}$ control switching block & $0.37 \mathrm{uW}$ \\
\hline $\mathrm{V}_{\mathrm{DD}}$ control circuit & $4.47 \mathrm{~mW}$ \\
\hline $\mathrm{V}_{\text {th }}$ control circuit & $1.022 \mathrm{nW}$ \\
\hline $\mathrm{I}_{\mathrm{w}}$ monitor & $6.12 \mathrm{~mW}$ \\
\hline $\mathrm{I}_{\mathrm{sw}}-\mathrm{I}_{\text {leak }}$ comparator & $3.45 \mathrm{uW}$ \\
\hline $\mathrm{I}_{\text {subth }} \mathrm{I}_{\text {sub }}$ comprator & $5.96 \mathrm{~mW}$ \\
\hline Modified $\mathrm{I}_{\text {subth }}-\mathrm{I}_{\text {sub }}$ & $5.43 \mathrm{~mW}$ \\
\hline
\end{tabular}

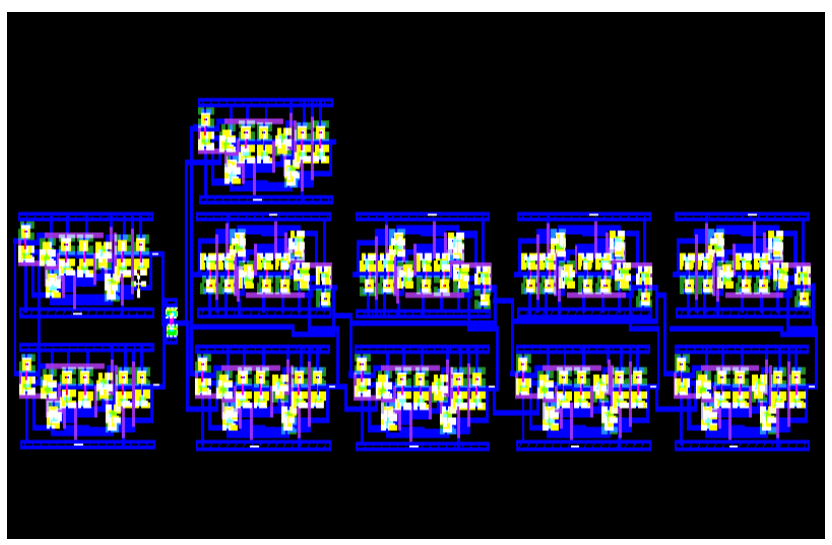

Figure 10: The implemented Layout of Delay Detector.

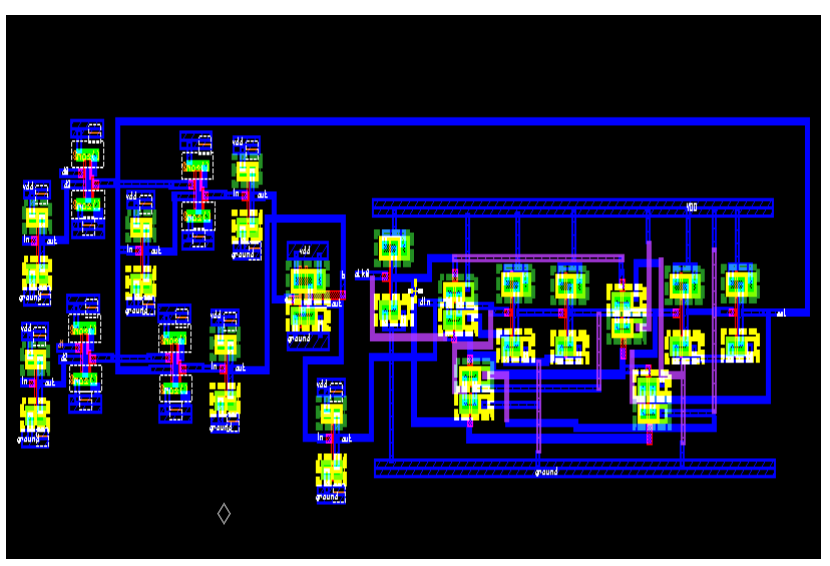

Figure 11: The implemented Layout of $V_{d d} / V_{t h}$ control block. 


\section{CONCLUSION}

We have implemented both the Delay and Power monitoring schemes to reduce the power consumption. After completion of these schemes, during the layout construction (LVS) of delay monitor the power has been reduced (known by post layout simulation). The main challenge of schemes is the designing of comparator with a reduction of voltage drop. Though it may have some challenges, the power schemes are very useful for the reduction of leakage power, which plays an important factor in total power dissipation. Finally, we can say that the total power consumption has been efficiently reduced by $18 \%$. And these schemes are very useful to reduce any type of leakage power in both active and standby modes.

\section{ACKNOWLEDGEMENTS}

The authors would like to thank their parents for their support and P. Magesh Kannan for his valuable suggestions and advice.

\section{REFERENCES}

[1] Masahiro Nomura, Yoshifumi Ikenaga, Koichi Takeda, yoetsu Nakazawa, "Delay and power monitoring schemes for minimizing power consumption by means of supply and threshold Voltage control in active and standby modes", in IEEE Journal of solid state circuits, vol.41, Apr.2006, pp. 805-814.

[2] V. R. von Kaenel, M. D. Pardoen, E. Dijkstra, and E. A. Vittoz, "Automatic adjustment of threshold and supply voltages for minimum power consumption in CMOS digital circuits," in IEEE Symp. Low Power Electronics Dig. Tech. Papers, Oct. 1994, pp. 78-79.

[3] J. T. Kao, M. Miyazaki, and A. P. Chandrakasan, “A 175$\mathrm{mV}$ multiply accumulate unit using an adaptive supply voltage and body bias architecture," IEEE J. Solid-State Circuits, vol. 37, no. 11, pp. 1545-1554, Nov. 2002.

[4] K. Nose and T. Sakurai, "Optimization of $V_{D D}$ and $V_{T H}$ for low power and high-speed applications," Proc. ASP-DAC, pp. 469-474, Jan. 2000.

[5] T. Kuroda, K. Suzuki, S. Mita, T. Fujita, F. Yamane, F. Sano, A. Chiba, "Variable supply volt zoltage scheme for low power high speed CMOS digital design," IEEE J. of solid state Circuits, vol.33,pp.454-462, Mar.2003.

[6] C. Neau and K. Roy, "Optimal body bias selection for leakage improvement and process compensation over different technology generations," in Proc. IEEE Int. Symp. Low Power Electronics and Design (ISLPED), Aug. 2003, pp. 116-121.
[7] M. Nakai, S. Akui, K. Seno, T. Meguro, T. Seki, T. Kondo, A. Hashiguchi, H. Kuwahara, K. Kumano, and M. Shimura, "Dynamic voltage and frequency management for a lowpower embedded microprocessor," IEEE J. Solid-State Circuits, vol. 40, no. 1, pp. 28-35, Jan. 2005.

[8] M. Nomura, Y. Ikenaga, K. Takeda, , Y. Aimoto, and Y. Hagihara, "Monitoring scheme for minimizing power consumption by means of supply and threshold voltage control in active and standby modes," in Symp. VLSI Circuits Dig. Tech. Papers, Jun. 2005, pp. 308-311.

[9] R. Kumar, C.P. Ravikumar, "Leakage power estimation for deep submicron circuits in an ASIC design environment", Design Automation Conference on VLSI Design, ASP-DAC 2002, 7-1 1 Jan. 2002, pp. 45 - 50.

[10] K. Roy, S. Mukhopadhyay, H. Mahmoodi-Meimand, "Leakage current mechanisms and leakage reduction techniques in deep-sub micrometer CMOS circuits", IEEE, Vol. 91, No. 2, Feb. 2003, pp. 305 - 327.

[11] O. Semenov, A. Pradzynski, M. Sachdev, "Impact of gate induced drain leakage on overall leakage of submicrometer CMOS VLSI circuits", IEEE Transactions on Semiconductor Manufacturing, Vol. 15, No. 1, Feb. 2002, pp. 9 - 18.

Pavan K Tadavarthi was born in Narasaraopet, Andhra Pradesh, India on May 15, 1988. He received his Bachelor of Technology degree in Electronics \& Instrumentation Engineering (E.I.E.) from S.V.E.C, Tirupathi which is affiliated to J.N.T.University, Ananthapur, A.P. in the year 2009. Currently he completed his M.Tech. Programme in VLSI Design from VIT University, Vellore, Tamil Nadu in the year 2011. His areas of interest are Digital IC Design, ASIC Design and Low power IC Design. And Mr. T.K. Pavan is a member of the Instrumentation Society of India (ISOI) student chapter.

Nagaraju Vutukuri was born in Narasaraopet, Andhra Pradesh, India on March 08, 1987. He received his Bachelor of Technology degree in Instrumentation \& Control Engineering (I.C.E.) from N.E.C, Narasaraopet which is affiliated to J.N.T.University, A.P. in the year 2008. Currently he completed his M.Tech. Programme in Communication Engineering from VIT University, Vellore, Tamil Nadu in the year 2011. His areas of interest are Digital IC Design and Digital Communications. 